\title{
The Impact Transformational Leadership in Developing Psychological Empowerment
}

\author{
Professor Hülya Gündüz Çekmecelioğlu \\ Faculty of Economics and Administrative Sciences \\ Kocaeli University, Turkey \\ Associate Professor Gönül Kaya Özbağ \\ Maritime Faculty \\ Kocaeli University, Turkey
}

\begin{abstract}
The aim of this study is to analyze the relationship between transformational leadership and psychological empowerment in a sample of 270 respondents. Four dimensions of transformational leadership have been proposed as an instrument to enhance individuals' perception of psychological empowerment. The findings confirm a positive link among idealized influence, intellectual stimulation and psychological empowerment. By linking each dimension of transformational leadership to four dimensions of psychological empowerment, the study draws paths from leadership behaviour to employee empowerment and thus the current findings provide valuable insights both for leadership and empowerment literature.
\end{abstract}

Keywords: Transformational Leadership, Psychological Empowerment

\section{Introduction}

There is substantial evidence that psychological empowerment (PE) components including meaning, competence and impact are found to be significantly related to desired individual outcomes such as job satisfaction (Thomas \& Tymon, 1994; Menon, 1999; Kirkman \& Rosen, 1999; Carless, 2004; Wang \& Lee; 2009; Chang , Shih \& Lin, 2010), organizational commitment (Meyer \& Allen, 1991 ; Lashinger et al., 2000; 2009; Kirkman \& Rosen, 1999; Joo \& Shim, 2010; Chiang \& Hsieh, 2012), innovative behaviour (Knol \& Van Linge, 2009; Spreitzer, 1995), performance (Siegler \& Pearson, 2000; Chiang \& Hsieh, 2012) intrinsic motivation and creativity (Zhang \& Bartol, 2010; Sun, Zhang, \& Chen 2012; Çekmecelioğlu \& Özbağ, 2014; 2016). On the other hand, there is a a large amount of evidence that PE decreases job strain and job stress (Spreitzer et al. 1997; Spreitzer, Kizilos, \& Nason, 1997; Lautizi, Laschinger \& Ravazzolo; 2009) and turnover intentions (Griffeth, Hom, \& Gaertner, 2000; De Villiers \& Stander; 2011; Albrecht $\&$ Andreetta, 2011; Bhatnagar, 2012) that impact organizations performance.

Especially in today's fast changing business environment and knowledge economy there is an increasing demand on empowered employees. Tough global competition and increasing rate of technological advancement have forced employees to achieve more complex and time pressured jobs. These challenges have lead the academicians and practitioners to seek the management practices that empower employees to take initiative, embrace risk, encourage innovation and cope with uncertainty in the face of increasing competition (Walton, 1985; McDuffie, 1995). It's apparent from the past literature that researches generally examined the consequences of PE in the workplace. Despite the growing interest on PE, relatively little is known about antecedents of PE. Researchers on PE have indicated that variables such as personality traits, demographic factors, work design characteristics, supervisory support, organization's climate and culture and are positively associated with PE (Spreitzer, 1995; Siegall \& Gardner, 2000; Koberg et al. 1999; Sigler and Pearson 2000; Menon 2001). Though transformational leadership (TL) may be a critical determinant of PE, few studies have examined the direct relationship between TL and PE. By enhancing the motivational mechanism of PE, transformational leaders (TLs) can energise aspect of empowerment (Menon, 2001). TL includes empowering behaviors such as influencing followers' self-esteem and selfworth (Shamir et al., 1993), selfefficacy and organisational goal internalisation (Conger \& Kanungo, 1998; Menon, 2001), self-confidence and meaning (Avolio et al., 2004), personal and social identity (Kark, Shamir, \& Chen, 2003). Empirical evidence provided by previous studies leads to consider that TL may be a major determinant of PE. Therefore, the purpose of the present study is to analyse the role of TL in developing PE.

\section{Literature Review And Hypotheses}

\subsection{Psychological Empowerment}

Despite the concept of empowerment has gained increased popularity in the management field, many scholars still reduce the meaning of it to delegate or share power with subordinates. 
This idea of delegation and the decentralization of decision-making power is widespread in describing the empowerment concept (Burke, 1986; Kanter, 1983). Conger \& Kanungo critically analyze this and propose that empowerment should be viewed as a motivational construct that means "to enable" rather than simply "to delegate". They claim that there are various other conditions of empowering besides delegation, resource sharing or participation. By using Bandura's self-efficacy notion (1986) they defined empowerment "as a process of enhancing feelings of selfefficacy among organizational members through the identification of conditions that foster powerlessness and through their removal by both formal organizational practices and informal techniques of providing efficacy information" (1988: 474). Accordingly, they identify the principal contextual factors that contribute to the lowering of self-efficacy beliefs in organizational members that are organized into four categories such as organizational, supervisory style, reward systems, and job design (1988: 476).

Afterwards Thomas and Velthouse (1990) described empowerment using motivational assumptions of the job design literature (Deci, 1975; Hackman \& Oldham, 1980; Bandura, 1986). Empowerment is defined as increased intrinsic task motivation, and their model identifies four cognitions as the basis for employee empowerment: impact ((the ability to affect or influence organizational outcomes), competence (sense of confidence in abilities that is similar to Conger and Kanungo's (1988) concept of self-efficacy,) meaningfulness (value and meaning of the task) and choice (selfdetermination with experienced sense of responsibility). In parallel both Conger and Kanungo (1988) and Thomas and Velthouse (1990), Spreitzer (1995) validated a measure of psychological empowerment manifested in four cognitions: meaning, competence, self-determination, and impact.

Meaning was described as "the value of a work goal or propose, judge in relation to an individual's own ideals or standards "(Speritzer, 1999; 40). Competence, the second cognition was equated with self efficacy, and described as "an individual's belief in his or her capability to perform activities with skill" (Spreitzer, 1999; p.40). According to Bandura (1989, p. 408), self-efficacy involves 'beliefs in one's capabilities to mobilise the motivation, cognitive resources, and courses of action needed to meet given situational demands. Third, self-determination was described as "an individual's sense of having choice in imitating and regulating action" (Spreitzer, 1999, p.41). Finally, impact was defined as "the degree to which an individual can influence strategic, administrative or operating outcomes in the organization or larger environment" (Spreitzer, 1999, p.43). Impact is seen as control over one's environment or the belief that his/her actions are influencing the system (Thomas and Velthouse, 1990). Gagne et al. (1997; 1223) emphasized that these four dimensions as a "gestalt of four types of feeling that are related yet somewhat independent of one another".

A review of the literature demonstrates that employees' perceptions of the work environment and culture influence the empowerment perceived by an employee (Spreitzer, 1996; Mallak \& Kurstedt, 1996; Robbins et al., 2002; Martin \& Bush, 2006). Since managers and leaders are the key sources that shape and design an organization's culture, they may also have a substantial impact on individuals' empowerment. On the other hand, Quinn and Spreitzer's (1997; 41) claim that management can create a context that is more empowering but at the same time employees must choose to be empowered. In other words, empowerment can really only be said to have occurred if the individual believes that they have been empowered (Dainty et al., 2002: Greasley et al; 2007). Accordingly, employees feel fully powered when they perceive that the task is worthwhile (meaning), they have the necessary skills and abilities (competence) for better job performance, their behavior will have some influence on what happens in the environment (impact) and they have a choice about how to do their jobs (self-determination) (Quinn \& Spreitzer's, 1997; Siegler \& Pearson, 2000; Robbins et al., 2002).

\subsection{The Relationship Between Transformational Leadership and Psychological Empowerment}

It's apparent from the above discussion that employee empowerment may be viewed as a cognitive state that requires to combine organizational and psychological domains. In this sense TL can be a central mechanism to promote greater feelings of PE. Before exploring the significant relationship between TL and PE it will be beneficial to briefly describe the characteristics of TL. According to Bass \& Avolio (1994) TL have four unique but interrelated behavioural components including idealized influence (which was before named charisma), inspirational motivation, intellectual stimulation and individualized consideration. Idealized influence refers pride in followers for being associated with the leader due to his / her charismatic, powerful and confident actions. TLs possess a vision that provides direction and meaning for their followers and inspire followers to transcend their self-interest for the sake of the collective goals.

They do the right things and offer a model role for their followers by exhibiting moral and ethical behaviours that creates a sense of meaningfulness (Bass, 1985). TL could have stimulated agreements about priorities by emphasizing a higher purpose or worthy cause which may also facilitate taking greater responsibility for achieving a collective, meaningful and challenging goal (Conger \& Kanungo 1988; Quinn and Spreitzer, 1997; Bass, 1999; Menon, 2001). Accordingly, it is hypothesized; 
H1: Idealized influence dimension of TL is positively related with meaning dimension of PE.

H2: Idealized influence dimension of TL is positively related with competence dimension of $P E$.

H3: Idealized influence dimension of TL is positively related with self determination dimension of PE.

H4: Idealized influence dimension of TL is positively related with impact dimension of PE.

TL also enhances the cognitive states of empowerment by creation and presentation of an attractive vision of the future. Such inspirational motivation promotes feelings of self-efficacy (Conger \& Kanungo, 1988) and perceived competence (Thomas \& Velthouse 1990; Spreitzer 1995; Menon 1995; 2001) both of which are significant to the psychological experience of empowerment. The idealized influence and inspirational leadership aspects of TL prime the collective identity of the follower's self-concept (Kark \& Shamir, 2002). In addition to clearly articulating meaningful and inspirational goals, TLs enlarge followers' expectations, and communicating confidence that followers can achieve ambitious goals. Thus, by envisioning an attractive future TLs align followers' self-identities with their organization's values and mission which may satisfy their needs for self-determination, competence, and impact by being a member of an effective organization (Shamir et al., 1993; Sosik \& Jung, 2010).

H5: Inspirational motivation dimension of TL is positively related with meaning dimension of PE.

H6: Inspirational motivation dimension of TL is positively related with competence dimension of $P E$.

H7: Inspirational motivation dimension of TL is positively related with self determination dimension of PE.

H8: Inspirational motivation dimension of TL is positively related with impact dimension of PE.

The third component intellectual stimulation represents behaviors that challenge followers' imagination, creativity and innovation. Through intellectual stimulation, TLs encourage followers to challenge the status quo and to solve problems by trying out new approaches. Furthermore, they appreciate followers' ideas even if they are different from the traditional way of thinking (Sharma et al., 2012; Çekmecelioğlu \& Özbağ, 2016). They frequently emphasize the value of novel ideas and thus followers feel comfortable in proposing new alternatives or even taking risks (Shin \& Zhou 2003; Çekmecelioğlu \& Özbağ, 2016). TLs satisfy the psychological needs of employees such as need for autonomy, need for competence, need for impact (Van Den Broeck et al., 2016) by offering employees freedom and autonomy while they are accomplishing their tasks or stimulating them to criticize existing approaches and assumptions.

H9: Intellectual stimulation dimension of TL is positively related with meaning dimension of PE.

H10: Intellectual stimulation dimension of TL is positively related with with competence dimension of PE.

H11: Intellectual stimulation dimension of TL is positively related with self determination dimension of PE.

H12: Intellectual stimulation dimension of TL is positively related with impact dimension of PE.

Finally, TLs contributes to follower empowerment and satisfaction by listening them attentively and paying close attention to the difference needs and wishes of followers (Conger, 2014; Avolio et al. 2004). They treat each employee as an individual, demonstrate high concern and initiate an interest in the development of each employee by acting as a mentor or coach (Kark \& Shamir, 2002; Shibru \& Darshan, 2011; Snell et al.,2013). They also exhibit individualized consideration by showing general support for the efforts of followers, and by encouraging their autonomy and empowering them to take on more responsibility for future development and growth (Bass, 1985; Avolio \& Bass; 1995). Such behaviours encourage followers to take more responsibilities in order to develop to their full potential (Bass, 1985), thereby increasing their perceived competence associated with PE (Spreitzer, 1995).

H13: Individualized consideration dimension of TL is positively related with meaning dimension of PE.

H14: Individualized consideration dimension of TL is positively related with with competence dimension of $P E$.

H15: Individualized consideration dimension of TL is positively related with self determination dimension of PE.

H16: Individualized consideration dimension of TL is positively related with impact dimension of $P E$.

Reviewing the literature reveals that there is a positive relationship between TL and followers' PE (Kark et al., 2003; Avolio et al., 2004; Allameh et al., 2012; Dust et al.,2014; Pradhan et al., 2017; Abdulrab et al.,2017). However, past studies mostly focus on the mediating role of PE in the relationship between TL and variables such as organizational commitment (Avolio, Zhu, Koh, \& Bhatia, 2004), organizational identification (Zhu et al., 2012), social identification (Kark et al., 2003), employee task performance and organizational citizenship behavior (Dust et al., 2014), employees' knowledge sharing intention (Han, Seo, Yoon, and Yoon 2016).

There are a few studies that investigate the direct relationship between the dimensions of TL and PE (e.g. Khanmohammadi \& Mohseni 2010; Allameh et al., 2012; Pradhan et al., 2017; Abdulrab et al., 2017) and thus it seems important to gain a more comprehensive understanding of the empowering influence of TLs. 


\section{Methodology}

\subsection{Selection of Sample and Respondents Demographics}

In order to empirically investigate the hypotheses, tools such as e-mail, letter and face to face interviews are used for gathering data from the managers-top, middle or first line. Using the documents of Kocaeli Chamber of Commerce, 40 firms among 650 are identified as the target group of the research because of their availableness. Of the 270 respondents $137(51 \%)$ were men, and $133(49 \%)$ were women. The majority of the participants $183(68 \%)$ are married and ranged in age from 30 to 40 years 148 (55\%). Of the participants, $\% 53$ had university educations and \%25 had master education, $\% 40$ were first line managers, $\% 46$ were middle managers and $\% 12$ were top managers. Data from 270 employees have been evaulated by using of the SPSS 13.0 program

\subsection{Measures}

To test the above hypotheses, multi-item scales adopted from prior studies for the measurement of constructs were used. (1999). To measure TL the Multifactor Leadership Questionnaire Form 5X was used (Bass \& Avolio, 1995). PE was measured by 12 items developed from the study of Spreitzer (1995). The scale contains three items for each of the four components of PE: meaning, competence, self-determination and impact. All items were measured on a five point Likert-type scale where (1) strongly disagree to (5) strongly agree.

\subsection{Data Analysis And Results}

To test the reliability of the scales used in the study, Cronbach Alpha scores were calculated for each scale. The Cronbach Alpha scores for each scale were good with overall Alpha reported of 0.70-0.87. Furthermore, in order to identify the underlying structure of various measures exploratory factor analysis using principle components of factor extraction and Varimax rotation techniques was performed. It is found that one item in idealized effect dimensions of TL constitutes a different factor alone and also have a low correlation with all items. After throwing out this item factor analysis is employed again (Hatcher, 1994). As a cut-off loading was used 0.40. Most factor loadings were above 0.50 which can be assumed a high level of significance. The results from our factor analysis of the measurement items for each of the subscales (Table 1) imply that measures used in this study have construct validity (Nunnally, 1978). The Alpha reliabilities of the factor were 0.84 (intellectual stimulation), 0.87 (idealized influence), 0.70 (inspirational motivation), 0.75 (individualized consideration), 0.89 (meaning), 0.81(competence), 0.78 (self determination), 0.88 (impact) respectively (Table 3). The factor loadings of transformational leadership and psychological empowerment scale are given in Table 1 and Table 2.

Table 1. Factor Loading of Transformational Leadership Scale Items

\begin{tabular}{|c|c|c|c|}
\hline $\begin{array}{l}\text { Factor } 1 \\
\text { Intellectual } \\
\text { stimulation }\end{array}$ & $\begin{array}{l}\text { Factor } 2 \\
\text { Idealized } \\
\text { influence }\end{array}$ & \begin{tabular}{|l|} 
Factor 3 \\
Individualized \\
consideration
\end{tabular} & $\begin{array}{l}\text { Factor } 4 \\
\text { Inspirationa } \\
\text { l motivation }\end{array}$ \\
\hline $\begin{array}{l}.886 \\
.880 \\
.823 \\
.680\end{array}$ & $\begin{array}{l}.818 \\
.773 \\
.756 \\
.727 \\
.668 \\
.662 \\
.582\end{array}$ & $\begin{array}{l}.642 \\
.635 \\
.569 \\
.435\end{array}$ & 列 \\
\hline
\end{tabular}


Table 2. Factor Loading of Psychological Empowerment Scale Items

\begin{tabular}{|l|l|l|l|}
\hline $\begin{array}{l}\text { Factor 1 } \\
\text { Meaning }\end{array}$ & $\begin{array}{l}\text { Factor 2 } \\
\text { Competence }\end{array}$ & $\begin{array}{l}\text { Factor 3 } \\
\text { Self } \\
\text { Determinatio } \\
\text { n }\end{array}$ & $\begin{array}{l}\text { Factor 4 } \\
\text { Impact }\end{array}$ \\
\hline .921 & & & \\
.907 & & & \\
.887 & & & \\
& .873 & & \\
& .867 & .872 & \\
& .821 & .862 & .919 \\
& & & .895 \\
& & & \\
\hline
\end{tabular}

\subsection{Correlation Analysis}

We calculated means and standart deviations for each variable and correlation matrix of all variables. Means, standard deviations, reliabilities and correlations among all scales used in the analyses are shown in Table 3.

A correlation analysis was performed to examine interaction relationships among the variables. The results of shows us that there is two level relationships among variables with a significance level of $p<0.01$. The dimensions of TL such as intellectual stimulation, idealized influence, individualized consideration and inspirational motivation have significant positive correlations with meaning, competence, self determination, impact dimensions of PE.

Table 3. Descriptive Statistic, correlations and alpha reliabilities of the mesuares

\begin{tabular}{|c|c|c|c|c|c|c|c|c|c|c|c|c|}
\hline Variables & & $\begin{array}{l}\text { Mea } \\
\text { n }\end{array}$ & $\begin{array}{l}\text { Std } \\
\text { D. }\end{array}$ & 1 & 2 & 3 & 4 & 5 & 6 & 7 & 8 & 9 \\
\hline $\begin{array}{l}\text { Intellectual } \\
\text { stimulation }\end{array}$ & 1 & 3.73 & .73 & $\begin{array}{l}\text { a. } \\
(0.84)\end{array}$ & $\begin{array}{l}.595 * \\
*\end{array}$ & $\begin{array}{l}.762^{*} \\
*\end{array}$ & $\begin{array}{l}.731 * \\
*\end{array}$ & $.435^{* *}$ & $\begin{array}{l}.292 * \\
*\end{array}$ & $\begin{array}{l}.338 * \\
*\end{array}$ & $\begin{array}{l}.239 * \\
*\end{array}$ & $\begin{array}{l}.416^{*} \\
*\end{array}$ \\
\hline $\begin{array}{l}\text { Idealized } \\
\text { influence }\end{array}$ & 2 & 3.75 & .70 & & \begin{tabular}{|l|}
$a$ \\
$(0.87)$
\end{tabular} & $\begin{array}{l}.529 * \\
*\end{array}$ & $\begin{array}{l}.711 * \\
*\end{array}$ & $.458 * *$ & $\begin{array}{l}.261^{*} \\
*\end{array}$ & $\begin{array}{l}.300 * \\
*\end{array}$ & $\begin{array}{l}.218 * \\
*\end{array}$ & $\begin{array}{l}.395^{*} \\
*\end{array}$ \\
\hline $\begin{array}{l}\text { Individualize } \\
d \\
\text { consideration }\end{array}$ & 3 & 3.49 & .80 & & & a (.70) & $\begin{array}{l}.472 * \\
*\end{array}$ & $.372 * *$ & $\begin{array}{l}.159 * \\
*\end{array}$ & $\begin{array}{l}.304 * \\
*\end{array}$ & $\begin{array}{l}.273^{*} \\
*\end{array}$ & $\begin{array}{l}.372 * \\
*\end{array}$ \\
\hline $\begin{array}{l}\text { Inspirational } \\
\text { motivation }\end{array}$ & 4 & 3.64 & .60 & & & & a (.75) & $.349 * *$ & $\begin{array}{l}.215^{*} \\
*\end{array}$ & $\begin{array}{l}.282 * \\
*\end{array}$ & $\begin{array}{l}.248 * \\
*\end{array}$ & $\begin{array}{l}.351 * \\
*\end{array}$ \\
\hline Meaning & 5 & 4.18 & .77 & & & & & $\mathrm{a}(.89)$ & $\begin{array}{l}.584 * \\
*\end{array}$ & $\begin{array}{l}.480^{*} \\
*\end{array}$ & $\begin{array}{l}.390^{*} \\
*\end{array}$ & $\begin{array}{l}.780^{*} \\
*\end{array}$ \\
\hline Competence & 6 & 4.32 & .65 & & & & & & $\mathrm{a}(.81)$ & $\begin{array}{l}.579 * \\
*\end{array}$ & $\begin{array}{l}.353 * \\
*\end{array}$ & $\begin{array}{l}.777 * \\
*\end{array}$ \\
\hline $\begin{array}{l}\text { Self } \\
\text { determination }\end{array}$ & 7 & 3.96 & .75 & & & & & & & $\mathrm{a}(.78)$ & $\begin{array}{l}.530 * \\
*\end{array}$ & $\begin{array}{l}.823^{*} \\
*\end{array}$ \\
\hline Impact & 8 & 3.80 & .85 & & & & & & & & $\mathrm{a}(.88)$ & $\begin{array}{l}.551 * \\
*\end{array}$ \\
\hline $\begin{array}{l}\text { Psychological } \\
\text { empowerment }\end{array}$ & 9 & 4.06 & .59 & & & & & & & & & \\
\hline
\end{tabular}

** Correlation is significant at the 0.01 level (2-tailed). 


\subsection{Model Testing Results}

A regression analysis was performed to examine the effects of dimensions of TL on meaning, competence, self determination and impact (Table 4). Model 1 shows us that individualized consideration and intellectual stimulation positively affects meaning dimension of $\mathrm{PE}$ with $\mathrm{p}<0.01$ significance level. Model 2 indicates that individualized consideration and intellectual stimulation positively affects competence dimension of $P E$ with $p<0.01$ significance level. Furthermore Model 2 indicates that idealized influence has positive effect on competence with $p<0.05$ significance level. Also, Model 3 shows us that intellectual stimulation positively affects self determination with $p<$ 0.01 significance level. The findings of Model 4 shows us individualized consideration has positive effects on impact dimension of PE. Finally, The Model 4 indicates that individualized consideration and intellectual stimulation positively affects $\mathrm{PE}$ with $\mathrm{p}<0.05$ and $\mathrm{p}<0.05$ significance level. The results of the research show us that many of our hypotheses have been verified. Interpretation of $\mathrm{R}^{2}$ values and $\mathrm{F}$ values results from regression analysis can be found significant and acceptable in social sciences and the other concerned subjects.

Table 4. The Effects of the Dimensions of Transformational Leadership on Dimensions of Psycgological Empowerment and Psycgological Empowerment

\begin{tabular}{|c|c|c|c|c|c|}
\hline Independents & \begin{tabular}{ll}
\multicolumn{2}{l}{ Meaning } \\
Model 1 \\
$\beta$
\end{tabular} & $\begin{array}{l}\text { Competence } \\
\text { Model } 2 \\
\beta\end{array}$ & $\begin{array}{l}\text { Self } \\
\text { Determination } \\
\text { Model } 3 \\
\beta \quad t\end{array}$ & $\begin{array}{l}\text { Impact } \\
\text { Model 4 } \\
\beta\end{array}$ & $\begin{array}{l}\text { Psychological } \\
\text { empowerment } \\
\text { Model 5 } \\
\beta \quad t\end{array}$ \\
\hline $\begin{array}{l}\text { Intellectual } \\
\text { stimulation }\end{array}$ & $.3723 .01 * *$ & $\begin{array}{ll}326 & 3.37 * *\end{array}$ & $.2192 .25^{* *}$ & $\begin{array}{ll}.043 & .435\end{array}$ & $\begin{array}{ll}265 & 2.84 * *\end{array}$ \\
\hline $\begin{array}{l}\text { Inspirational } \\
\text { motivation }\end{array}$ & .066 .372 & $\begin{array}{ll}040 & .432\end{array}$ & .003 .035 & $\begin{array}{ll}.069 & .675\end{array}$ & $\begin{array}{ll}.012 & 1.22\end{array}$ \\
\hline $\begin{array}{l}\text { Individualized } \\
\text { consideration }\end{array}$ & $.032 \quad .312$ & $.2652 .48^{* * *}$ & $\begin{array}{ll}.062 & .585\end{array}$ & $.1891 .75^{*}$ & $\begin{array}{ll}.004 & .009\end{array}$ \\
\hline Idealized influence & $\begin{array}{l}.339 \\
3.96^{* *}\end{array}$ & $.1992 .85^{*}$ & $.100 \quad 1.39$ & .001 .001 & $2.27 *$ \\
\hline $\begin{array}{l}\text { Model F } \\
\text { Model R² }\end{array}$ & $\begin{array}{l}20.22 * * \\
0.227\end{array}$ & $\begin{array}{l}8.43^{*} \\
.100\end{array}$ & $\begin{array}{l}9.32 * * \\
.111\end{array}$ & $\begin{array}{l}5.76^{* *} \\
0.66\end{array}$ & $\begin{array}{l}16.02 * * \\
.183\end{array}$ \\
\hline $\begin{array}{l}* \text { Significant at } 0,05 \\
* * \text { Significant at } 0,0\end{array}$ & $\begin{array}{l}\text { ne tailed) } \\
\text { one tailed) }\end{array}$ & & & & \\
\hline
\end{tabular}

\section{Conclusion}

The present study has contributed to the current literature by investigating the role of TL dimensions which are idealized influence, inspirational motivation, intellectual stimulation, individualized consideration and on four dimensions of PE including meaning, competence, self determination and impact. The findings of the study are consistent with earlier researches demonstrating that there is a positive and significant relationship between TL and PE (Kark et al., 2003; Avolio et al., 2004; Avey et al., 2008; Allameh et al., 2011; Krishnan, 2012; Fang-guo, 2013; Dust et al., 2014; Balaji \& Krishnan, 2014; Jha, 2014; Pradhan et al., 2017; Abdulrab et al.,2017) even though not all the hypotheses of the research are supported ( particularly, H3, H4, H5, H6, H7, H8, H12, H13 and H15). By linking each dimension of TL to four dimensions of PE, the study draws paths from leadership behaviour to employee empowerment and thus the current findings provide valuable insights both for leadership and empowerment literature.

To enhance greater feelings of PE organizations needs leaders who influence employees to view the organization's vision as meaningful and inspiring and feel that they're engaged with meaningful and impactful work (Sosik \& Jung, 2010; Dust et al., 2014; Pradhan et al., 2017). Understanding employee needs and concerns, discovering what motivates each individual and then creating a supportive atmosphere that promotes employee development and growth are also the features of TLS contributing to greater feelings of PE. Besides, TLs also stimulate feelings of perceived competence or self-efficacy by demonstrating mentoring or coaching capabilities, helping followers to exceed their knowledge and skills and providing optimal conditions for learning with regular feedback. They earn the admiration of followers by being optimistic about the future, adhering to high ethical standards, promoting outside-the-box thinking and showing confidence in their abilities. It's apparent from the above discussion that TLs and employees who are psychologically empowered may ensure various ranges of organizational rewards for both parties. Therefore, firms should organize training programs for leaders that are designed to acquire behavioural dimensions of TL, which in turn help to create an environment that is conducive to growth and development. Although, this study demonstrates the linkages between TL and PE, it has some limitations that must be considered. 
First, the data were collected from a single source that can create a potential threat for common method variance. Second, there may be moderators or mediators that can help to get a more comprehensive understanding of the relationship. Thus, future studies can enrich their model by adding variables that intervene in the relationship of leadership to empowerment such as personality, organizational climate, motivation, job satisfaction, commitment etc. Lastly, the study sample was from a Turkish private firm setting, where national and leadership culture may be different from West countries. Therefore, more cross-cultural and comparative studies are necessary to improve our understanding.

\section{References}

Abdulrab Mohammed, Zumrah Abdul Rahim, Almaamari Qais, Al-Tahitah Ali (2017). Transformational Leadership and Psychological Empowerment in Malaysian Public Universities, Research on Humanities and Social Sciences, 7 (24), 98-105.

Albrecht, S. L., \& Andreetta, M. (2011). The Influence of Empowering Leadership, Empowermentand Engagement on Affective Commitment and Turnover Intentions in Community Health Service Workers, Leadership in Health Services, 24(3), 228 - 237.

Allameh SM, Heydari M, Davoodi SM. (2012) Studying the relationship between transformational leadership and psychological empowerment of teachers in Abade Township. ProcediaSocial and Behavioral Sciences 31;31:224-30.

Avey, J. B., Hughes, L. W., Norman, S. M., \& Luthans, K. W. (2008). Using positivity, transformational leadership and empowerment to combat employee negativity. Leadership \& Organization Development Journal, 29(2), 110-126.

Avolio, B. J., \& Bass, B. M. (1995). Individual consideration viewed at multiple levels of analysis: A multi-level framework for examining the diffusion of transformational leadership. The Leadership Quarterly, 6, 199-218.

Avolio, B.J., Zhu, W., Koh, W. and Bhatia, P. (2004), "Transformational leadership and organizational commitment: mediating role of psychological empowerment and moderating role of structural distance", Journal of Organizational Behavior, Vol. 25 No. 8, pp. 951-968.

Bandura, A. (1986). Social Found Ations Of Thought And Action: A Social-Cognitive View, Englewood Clivs, Nj: PrenticeHall.

Bass, B. M. (1985). Leadership and Performance Beyond Expectation. New York: The Free Press.

Bass, B. M. (1999).Two decades of research and development in transformational leadership. Eur J Work Organ Psy. 8(1):932.

Burke, W. (1986). Leadership as empowering others. In S. Srivastra (Ed.), Executive power (pp. 51-77). San Francisco: Jossey-Bass.

Jyotsna Bhatnagar (2012). Management of innovation: role of psychological empowerment, work engagement and turnover intention in the Indian context, The International Journal of Human Resource Management, 23:5, 928-951.

Carless, S. A. (2004). Does psychological empowerment mediate the relationship between psychological climate and job satisfaction? Journal of Business and Psychology, 18(4), 405-425.

Chang, L. C., Shih, C. H., \& Lin, S. M. (2010). The mediating role of psychological empowerment on job satisfaction and organizational commitment for school health nurses: A cross-sectional questionnaire survey. International Journal of Nursing Studies, 47(4), 427-433.

Chiang, C. F., \& Hsieh, T. S. (2012). The Impacts of Perceived Organizational Support and Psychological Empowerment on Job Performance: The Mediating Effects of Organizational Citizenship Behavior. International Journal of Hospitality Management, 3, 180-190.

Çekmecelioğlu, H.G., \& Özbağ, G.K. (2014). Linking Psychological Empowerment, Individual Creativity and Firm Innovativeness: A Research on Turkish Manufacturing Industry. Business Management Dynamics, 3(10), 01-13.

Çekmecelioğlu, H.G., \& Özbağ, G.K. (2016). Leadership and Creativity: The Impact of Transformational Leadership on Individual Creativity. Procedia - Social and Behavioral Sciences. 235. 243-249.

Conger, J.A. And Kanungo, R.N. (1988). The Empowerment Pocess: Integrating Theory And Practise, Academy Of Management Review, 13(3), pp. 471-482.

Conger, J. A., \& Kanungo, R. A. (1998). Charismatic leadership in organizations. Thousand Oaks, CA: Sage Publications.

Conger, J. A. (2014). Addressing the organizational barriers to developing global leadership talent. Organizational Dynamic 43, 198-204.

Dainty, A R J, Bryman, A and Price, A D F (2002). Empowerment within the UK construction sector. Leadership and Organization Development Journal, 23(5/6), 333-42.

De Villiers, J.R. \& Stander, M.W. (2011). Psychological empowerment, work engagement and turnover intention: The role of leader relationships and role clarity in a financial institution. Journal of Psychology in Africa, Vol. 21, No. 3:405412.

Deci E.L. (1975) Intrinsic Motivation, New York: Plenum. 
Dust, S.B., Resick, C.J. and Mawritz, M.B. (2014), "Transformational leadership, psychological empowerment, and the moderating role of mechanistic - organic contexts", Journal of Organizational Behavior, Vol. 35 No. 3, pp. 413-433.

Fang-guo, S. 2013. "Multilevel model of transformational leadership and service quality: Testing mediation role of psychological empowerment". Paper presented at the Management Science and Engineering (ICMSE), 2013 International Conference on.

Gagne, M., Senecal, C.B. and Koestner, R. (1997), "Proximal job characteristics, feelings of empowerment, and intrinsic motivation: a multidimensional model", Journal of Applied Social Psychology, Vol. 27 No. 14, pp. 122-40.

Greasley, K., Bryman, A., Dainty, A., Price, A., Naismith, N., \& Soetanto, R., (2007). Understanding empowerment from an employee perspective What does it mean and do they want it?. Team Performance Management Journal, 14(2), pp.39-55.

Griffeth R.W, Hom P W, Gaertner S, (2000). A Meta-Analysis of Antecedents and correlates of Employee Turnover: Update, Moderator tests, and Research implications for the next millennium “e. Journal of Management, vol. 26, No3, 463488.

Hackman, J. R. And Oldham, G. R. (1980). Work Redesign, Reading, Ma: Addison-Wesley.

Han, S. H., Seo, G., Yoon, S. W., \& Yoon, D.-Y. (2016). Transformational leadership and knowledge sharing: Mediating roles of employee's empowerment, commitment, and citizenship behaviors. Journal of Workplace Learning, 28(3), 130-149.

Jha, Sumi. (2014). Transformational leadership and psychological empowerment: Determinants of organizational citizenship behavior. South Asian Journal of Global Business Research. 3. 10.

Joo, B., \& Shim, J. H. (2010). Psychological empowerment and organizational commitment: The moderating effect of organizational learning culture. Human Resource Development International, 13(4), 425-441.

Kanter, R. M. (1983). The change masters. New York: Simon \& Schuster.

Kark, R., \& Shamir, B. 2002. The dual effect of transformational leadership: Priming relational and collective selves and further effects on followers. In B. J. Avolio \& F. J. Yammarino (Eds.), Transformational and charismatic leadership: The road ahead, vol. 2: 67-91. Amsterdam: JA1 Press

Kark, R., Shamir, B., \& Chen, G. (2003). The two faces of transformational leadership: Empowerment and dependency. Journal of Applied Psychology, 88, 246-255.

Khanmohammadi, O.M. \& Mohseni, A. (2010). "Studying the impact of leadership styles (transformational, transactional, non-interference) on psychological empowerment", 24th International Electricity Conference Proceedings, 251-255.

Kirkman, B.L. \& Rosen, B. (1999). Beyond self-management: Antecedents and consequences of team empowerment, in: Academy of Management Journal, 42, 58-74.

Knol, J. ve Van Linge, R. (2009). "Innovative Behaviour: The Effect of Structural and Psychological Empowerment on Nurses" Journal of Advanced Nursing, 65(2):359-370.

Krishnan, V. R. (2012). Transformational leadership and personal outcomes: empowerment as mediator. Leadership \& Organization Development Journal, 33(6), 550-563.

Koberg, C. S., Boss, W., Senjem, J. C., \& Goodman, E. A. (1999). Antecedents And Outcomes Of Empowerment: Empirical Evidence From The Health Care Industry. Group and Organization Management, 34(1): 71-91.

Laschinger, H.K.S., J. Finegan, J. Shamian \& S. Casier (2000). "Organizational Trust and Empowerment in Restructured Healthcare Settings: Effects on Staff Nurse Commitment." Journal of Nursing Administration 30(9): 413-25.

Laschinger H.K., Finegan J. \& Wilk P. (2009). Context matters: the impact of unit leadership and empowerment on nurses' organizational commitment. The Journal of Nursing Administration 39(5), 228-235.

Lautizi, M., Laschinger, H. K. S., \& Ravazzolo, S. (2009). Workplace empowerment, job satisfaction and job stress among Italian mental health nurses: An exploratory study. Journal of Nursing Management, 17(4), 446-452.

MacDuffie, J. P. (1995). Human resource bundles and manufacturing performance: Organizational Logic and flexible production systems in world auto industry. Industrial and Labor Relations Review, 48, 197-221.

Mallak, L. A., \& Kurstedt, H. A. (1996). Understanding and using empowerment to change organizational culture. Industrial management, 38(6), 8- 10.

Menon, S.T. (1999). Psychological Empowerment: Definition, Measurement and Validation, Canadian Journal of Behavioral Sciences, 31(3): 161-164.

Menon, S.T. (2001): Employee Empowerment: An Integrative Psychological Approach, in: International Review, 50 (1),153180.

Martin, C. A. \& A. J. Bush. (2006). "Psychological Climate, Empowerment, Leadership Style, and Customer-oriented Selling: An Analysis of the Sales Manager- Salesperson Dyad." Journal of Academy of Marketing Science 34 (3): 419-438.

Meyer, J., \& Allen, N. (1991). A three-component conceptualization of organizational commitment. Human Resource Management Review, 1, 64-98.

Pradhan, R.K., Panda, M. \& Jena, L.K. (2017), “Transformational leadership and psychological empowerment: the mediating effect of organizational culture in Indian retail industry", Journal of Enterprise Information Management, Vol. 30 No. 1, pp. 82-95. 
Robbins, T.L.; Crino, M.D \& Frendal, L.D. (2002). An Integrative Model of the Empowerment process. Human Resource Management Review, 12(3), 419- 443.

Shamir, B., House, R. J., \& Arthur, M. B. (1993). The motivational effects of charismatic leadership: A self-concept based theory. Organization Science, 4, 577-593.

Sharma, P. Nagar, P. and Pathak, S. (2012). Impact of Transformational Leadership on Creative Flexibility of Engineers in India. ProcediaSocial and Behavioral Sciences. 57: 555-559.

Shin, S.J.,\& Zhou, J (2003). Transformational leadership, conservation, and creativity : evidence from Korea. Academy of Management Journal, 46(6), 703-714.

Shibru, B., \& Darshan, G. M. (2011). Effects of transformational leadership on subordinate job satisfaction in leather companies in Ethiopia. International Journal of Business Management \& Economic Research, 3(5), $284-296$.

Sigler, T.H., Pearson, C. M. (2000). Creating an empowering culture: examining the relationship between organizational culture and perceptions of empowerment, Journal of Quality Management, Vol.5, pp.27-52.

Siegall, M., \& Gardner, S. (2000). Contextual factors of psychological empowerment. Personnel Review, $29(6), 703-722$.

Snell, R.S., Yi, Z., \& Chak, A.M.K. (2013). Representational predicaments for employees: Their impact on perceptions of supervisors' individualized consideration and on employee job satisfaction. International Journal of Human Resource Management, 24(8): 1646-1670.

Spreitzer, G. M. (1995). Psychological empowerment in the workplace: Dimensions, measurement, and validation. Academy of Management Journal, 38(5), 1442-1465.

Spreitzer, G. M., De Janasz, S. C. and Quinn. R. E. (1999) Empowered To Lead: The Role Of Psychological Empowerment In Leadership. Journal Of Organizational Behavior, 20, pp. 511-526.

Spreitzer, G., M. (1996). Social Structural Characteristics Of Psychological Empowerment”, Academy Of Management Journal, 39(2), pp.483-504.

Spreitzer, G., M., Kizilos, M., A., W., Nason, S. (1997). A Dimensional Analysis Of The Relationship Between Psychological Empowerment And Effectiveness, Satisfaction, And Strain, Journal Of Management, Vol(5), pp. 679-704.

Sosik, J. J., \& Jung, D. I. (2010). Full range leadership development: Pathways for people, profit and planet. New York, NY: Routledge.

Sun, Li-Yun; Zhang, Zhen; Qi, Jin; Zhen, Xiong Chen (2012). "Empowerment and Creativity: A cross- level investigation", Leadership Quarterly, 23(1), pp.55-65.

Thomas, K. W., Velthouse, B., A. (1990). Cognitive Elements Of Management Review, 15(4), pp. 666-681.

Thomas, K.W. \& Tymon, W. (1994). Does empowerment always work: understanding the role of intrinsic motivation and personal interpretation. Journal of Management Systems, 6 (3), 1-13.

Quinn, R.E. \& Spreitzer, G.M.(1997.) The road to empowerment: Seven questions every leader should consider. Organizational Dynamics, Autumn: 37-49.

Van Den Broeck A, Ferris DL, Chang C-H, Rosen CC. (2016). A review of self-determination theory's basic psychological needs at work. J. Manag. 42:1195-229.

Walton, R. E. (1985. "From control to commitment in the in the workplace", Harvard Business Review, vol. March/April, pp. 25-32.

Wang, G., Lee, P. (2009). "Psychological Empowerment and Job Satisfaction an Analysis of Interactive Effects". Group \& Organization Management Vol.34 No 3, pp.271- 296.

Zhang Xiaomeng \& Bartol Kathryn M. (2010). "Linking Empowering Leadership And Employee Creativity: The Influence Of Psychological Empowerment, Intrinsic Motivation, And Creative Process Engagement”, Academy Of Management Journal, 53, pp.1107-128.

Zhu, W., Sosik, J. J., Riggio, R. E., \& Yang, B. (2012). "Relationships between transformational and active transactional leadership and followers' organizational identification", The role of psychological empowerment. Journal of Behavioural and Applied Management, 13(3), 186-212. 